MATEC Web of Conferences 13, 04009 (2014)

DOI: $10.1051 /$ matecconf/ 20141304009

(C) Owned by the authors, published by EDP Sciences, 2014

\title{
Comparative Study between Programming Systems for Incremental Sheet Forming Process
}

\author{
Majid Moayedfar ${ }^{1,2}$, Ahmad Majdi Bin Abdul Rani ${ }^{1,2, \text { a, }}$ Pouria Salehi ${ }^{3}$, \\ Varaha Venkata Lakshmi Narasimha Rao Tad ${ }^{1}$ \\ ${ }^{1}$ Department of Mechianical Engineering, Universiti Technologi Petronas, 31750 Perak, Malaysia \\ ${ }^{2}$ Centre for Intelligent Signal and Imaging Research, Universiti Technologi Petronas, 31750 Perak, \\ Malaysia \\ ${ }^{3}$ Department of Mechianical Engineering, Universiti Putra Malaysia, 43400 UPM Serdang, Selangor, \\ Malaysia
}

\begin{abstract}
Incremental Sheet Forming (ISF) is a method developed to form a desired surface feature on sheet metals in batch production series. Due to a lack of dedicated programming system to execute, control and monitor the whole ISF, researchers tried to utilize programming systems designed for chip making process to suits for ISF. In this work, experiments were conducted to find suitability and quality of ISF parts produced by using manual CNC part programming. Therefore, ISF was carried out on stainless steel sheets using Computer Numerical Control (CNC) milling machines. Prior to running the experiments, a ball-point shaped tool made of bronze alloy was fabricated due to its superior ability to reduce the amount of friction and improve the surface quality of the stainless steel sheet metal. The experiments also employed the method of forming in negative direction with a blank mould and the tool which helped to shape the desired part quickly. The programming was generated using the MasterCAM software for the CNC milling machine and edited before transferring to the machine. However, the programming for the machine was written manually to show the differences of output date between software programming and manual programming. From the results, best method of programming was found and minimum amount of contact area between tool and sheet metal achieved.
\end{abstract}

\section{Introduction}

Incremental sheet forming (ISF) is a sheet metal forming technique where a sheet is formed into the final part by a series of small incremental deformations. Generally, the sheet is formed by a round tipped tool, typically 5 to $20 \mathrm{~mm}$ in diameter. The tool, which can be attached to a $\mathrm{CNC}$ machine, a robot arm or similar, indents into the sheet by about $1 \mathrm{~mm}$ and follows a contour for the desired part. It then indents further and draws the next contour for the part into the sheet and continues to do this until the full part is formed.

Forming of sheet metal contains different methods which are based on the use of punches and dies.

\footnotetext{
${ }^{a}$ Corresponding author: majdi@petronas.com.my
}

This is an Open Access article distributed under the terms of the Creative Commons Attribution License 2.0, which permits unrestricted use, distribution, and reproduction in any medium, provided the original work is properly cited. 
Conventional methods, such as stamping and drawing are always used in mass production, however, the high cost require primary investment and the total price for a sheet part in batch production rises, then the use of new sheet forming method becomes essential.

There are some parameters which are rather important in ISF than the other sheet forming process such as temperature, friction, feed rate, clamping force, tool path, tool shape and surface quality.

Some of the articles research on tool path $[3,4]$ and some others worked on simulation of the process $[5,6]$ to predict the final shape for their sheet parts.

Regarding the tools, it is used a simple indenter that moves toward the clamped sheet and the movements of the tool were dictated by $\mathrm{CNC}$ milling machine program which completes the final shape [2]. In some different experiments an indenter was fastened on a robot actuator and was forced point by point on the surface of the sheet. None of these methods could give the customers a reasonable final surface quality. The reason was because of the spring back phenomena, temperature effect and against job due to the differences between chipping process and forming process.

Although most of the articles presented their experiment with CAD/CAM software and then the experiments were followed by the surface milling methods [7, 8, 9], programming of CNC machines in ISF is still a big challenge. Here, advanced software which supports all forming and chipping icons in ISF is needed. Furthermore, changing the parameters and special factors in CNC machine software can sometimes work for ISF. However, there is lack between a chipping parameters and forming factors that cannot replace instead. In ISF tool path is more important than tool motion because the goal is not settling the sheet on a surface [10] which is mean, it is not necessary that the tool meets all parts of sheet surface to form the shape dissimilar than chipping method.

Presented work extracts the CAD data from CATIA version5 R20 and exports them to CAM software which is MasterCAM 2010 to extract the G codes and M codes and transfer them to the CNC milling machine. Some works use technical software in the final results to predict the valid results to show the numerical error and the accuracy of the process [3,11]. On the other hand, numerical error also is designed for CNC milling machining which is different with forming with $\mathrm{CNC}$ machine. Thus, only analysing software can detects the acceptability of an experiment after the production of final part which is lead to increase of wasting time. In addition, trial and error method in forming process is not accurate enough [5]. Therefore, the aim of this study is to determine the minimum contact area during the process of ISF using CNC milling machine to achieve the best surface quality by change in method of programming. In addition, it is tried to compare the programming systems applied for ISF process.

This parameter is a factor which illustrates the quality and accuracy of a part surface. Stretching, drawing, bending and ISF decrease the quality of surface. However, a process that consequents high surface quality is considerable. Final polishing can also help to improve the quality of sheet metal parts. This quality should be considered in both tool head and sheet surface. The indenter has a spherical head. This head makes some limitations in the forming processes. The smaller head causes the finer shapes. However, a very small head tool causes long time process and also it increases shear failure during the process. The method of production also has an effect on surface quality. Luo (2010) showed the differences of process in ISF. As can be seen, these differences effect on the surface quality [12].

Based on above literature, there are some criteria for ISF that should be focused such as forming parameters. As can be found the lack of an applicable tool is also obvious [1]. None of the studies work on tool improvement in terms of sheet stretch, friction reduction and surface quality. Also forming parameters are not considered and mentioned.

Because the process of ISF is a die-less forming, forming parameters effect on the rate of sheet stretch directly. Therefore, tool path optimization and simulation of predicting force do not effect on the whole process. In this study forming parameters is mostly considered to make ISF as an applicable method in industry.

The method of experiments based on trial and errors is considered to find out the optimum forming parameters. This method shows some critical points of sheet failure and also some optimize value for forming parameters that are spindle speed, feed rate and tool material. It is presented that 
programming has a direct effect on surface quality and friction, which results in high temperature in contact area.

\section{Methodology}

Both CNC milling and CNC lathe machine's controllers are designed to adjust with CAD/CAM software. Therefore, the parameters change as soon as the layout changes and the machine will be available for a new sequence. The programming is designed for chipping process though.

In this study, one experiment is designed to illustrate the differences between CAM software generated command lines and manual programming by the experts.

There are two different shapes of products which are designed for this purpose. A pyramid shape sheet part and one complicated asymmetric sheet part is considered, designed and drew by CATIA V5R20. Forming parameters and tool material were remained the same as they achieved from more related literatures $[1,2]$.

The clamping method also is the same for both designs which is complete clamping. This kind of clamping is more suitable for simple shape products. Hence, it is a proper choice for this experiment.

Bronze alloy is selected as the tool material for both parts. The tool is a cylindrical indenter with the dimension of $10 \mathrm{~mm}$ in diameter and $120 \mathrm{~mm}$ in length. Regarding to the increasing of the surface quality of parts and reducing of the friction in contact area during the forming process, the spherical head of indenter is fine polished. This clamping with the bronze alloy tool is shown on a CNC Mazak 3 axis milling machine in figure 1.

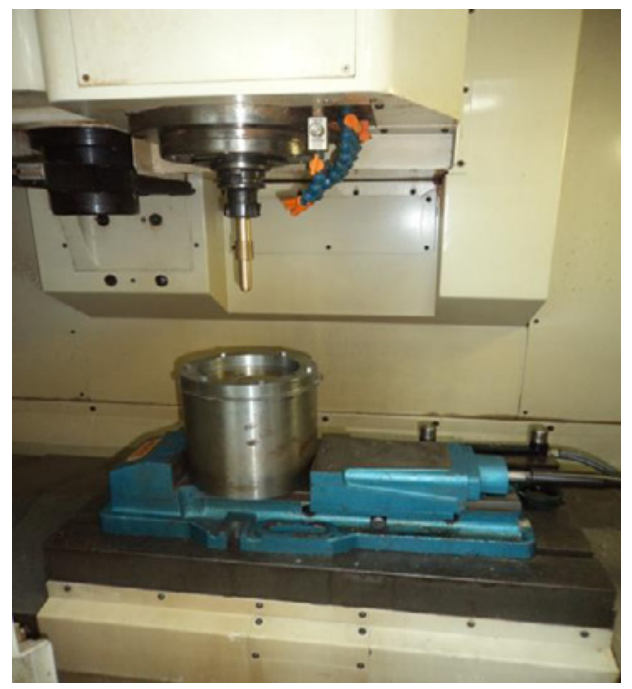

Figure 1. A set of ISF devices on a CNC milling machine

Programming is done by Master CAM software. All the values of $\mathrm{X}, \mathrm{Y}$ and $\mathrm{Z}$ axis are descending during the test, so the process can call negative ISF. Furthermore, die-less forming without any partial dies is better to be in negative form in order to avoid deviation. In addition, the experiment is done one more time with manual programming. Considering the complicated part is hard to programming, one more method is designed which was a combined of software $G$ and $M$ code generation with modification and simplify of commands manually.

Beside of last two mentioned experiments which were manual programming and software tool path generations; there is one more method of $\mathrm{G}$ and $\mathrm{M}$ code generation which is the combination of two methods of programming. For this reason, the parts are separated to some sections. The programming for every section is generated by the software of MasterCAM. Then the programs are linked and 
joined together manually which leads fewer commands line in complicated designs. Moreover, some parts such as corners, center and some locations which do not need to shape remain plane.

Finally, the result is compared by CMM machine to find the smoothest surface quality and accurate part in terms of method of programming.

\section{Results and Discussion}

Programming and tool path is a big challenge in ISF. An efficient strategy of forming which is selected for the second experiment, showed how a new strategy for ISF is needed using the latest version of CAM software, which is designed mostly for chipping process. Sometimes manual programming decreases the command lines almost 1000 times less than CAM system in a one simple shape. Some statistics software such as Excel can help manual programming in terms of functions and complexity of shapes also.

The results of this study shows that there is a gap between CAD/CAM system using milling process and with the forming process which leads to inaccurate and scratched parts. In addition, lack of specialized software for ISF in applicable projects found obviously.

For the pyramid shape part the number of 84000 command lines is generated by the software. This amount is reduced to 540 lines with manual programming with the same parameters, which results in huge advantages of manual programming for simple parts. Although this amount shows that there is big difference between all methods of programming, the complicated shape programming showed another results. Manual programming for complicated part was time consuming; therefore, it is not recommended for future work. 1.2 million Command lines for second part are generated in less than 10 minutes while manual programming preparation was 2 hours.

Regarding the surface quality for both parts, there were smoother surfaces when the programming selected in manual. Furthermore, these surfaces were also accurate enough which are met the tolerance of $\pm 0.1 \mathrm{~mm}$. This advantage is due to fewer contact area of tool and sheet metal. For forming of a sheet metal with ISF method it is not necessary that tool meets all part of sheet metal. That means by the shaping of the first part may another part forms. Therefore, amount of friction and also the amount of scratching reduces, which causes the better and smoother surface quality.

The amount of tool wear also in manual programming was lower than software programming due to fewer amount of connecting area between tool and sheet metal during the process. As can be seen, the tool wear which is the main cause of tool failure that effects on tool life is minor that makes this process more beneficial regarding the economical purpose.

This method results in a smoother surface and fewer scratched parts as it showed in CMM machine. All parts test and measured on the machine and the results noted. These results illustrated that combined method is more efficient for ISF process on CNC milling machine. The proper commands line than totally software programming and also the better and smother surface quality. Additionally, this method has the ability to generate $\mathrm{G}$ and $\mathrm{M}$ codes of complicated sheet parts in ISF process. Table 1 evaluates these three methods from grade 1 to grade 3, the higher grade the superior and desirable.

Table 1. Evaluation of three methods of programming

\begin{tabular}{|c|c|c|c|}
\hline & CAD/CAM System & $\begin{array}{c}\text { Manual } \\
\text { Programming }\end{array}$ & $\begin{array}{c}\text { Combined } \\
\text { Programming }\end{array}$ \\
\hline $\begin{array}{c}\text { Number of Command } \\
\text { Lines }\end{array}$ & 1 & 3 & 2 \\
\hline Time of Programming & 3 & 1 & 2 \\
\hline Surface Quality & 1 & 3 & 2 \\
\hline Amount of Scratched & 1 & 3 & 2 \\
\hline $\begin{array}{c}\text { Ability to programming } \\
\text { of complicated parts }\end{array}$ & 3 & 1 & 2 \\
\hline
\end{tabular}




\section{Conclusion}

Incremental sheet forming had been re-developed as a new prototype method recently. In order to improve the surface quality and accuracy it is needed to make this process more applicable in many parts of the industry. Therefore, this study tried to find some forming programming systems to reduce the working time, however, increase the surface quality and accuracy of sheet parts.

An efficient strategy for programming systems is considered and presented with two different shapes and sizes to compare the limitation and application of programming systems used in ISF process. Combined programming systems is selected for parts in high complicity of design to reduce the command lines for CNC milling machine and also to increase the surface quality by decreasing the contact area between tool and sheet metal and removing the redundancy in tool path. Therefore, an optimize tool path used by separation of part in to some sections for simplicity in combined programming.

As can be seen in table 1, three available programming systems are compared for ISF process regarding the results of this study

\section{Acknowledgments}

The author would like to records appreciation and thanks to the staff and technologist of Universiti Technology Petronas for assisting with laboratory work related to this research.

\section{References}

1. M. Moayedfar, Z. Leman, H. Mirabi, B.T.H.T. Baharudin, The effect of forming parameters on the sheet stretch in incremental sheet forming (ISF) process on CNC lathe machine. Advanced Materials Research, Trans Tech Publications. 634-638, 2894-2898 (2013)

2. M. Moayedfar, Z. Leman and B.T.H.T. Baharudin, Incremental Sheet Forming (ISF) of AISI 316 Stainless Steel Sheet Using CNC Milling Machine. Journal of Advances in Materials \& Processing Technologies. (2014)

3. M. Bambach, B. Taleb Araghi, G. Hirt, Strategies to improve the geometric accuracy in asymmetric single point incremental forming. Production Engineering. 3(2), 145-156 (2009)

4. G. Hirt, J. Ames, M. Bambach, R. Kopp, Forming strategies and process modelling for CNC incremental sheet forming. CIRP Annals-Manufacturing Technology. 53(1), 203-206 (2005)

5. M. Bambach, G. Hirt, Performance Assessment of Element Formulations and Constitutive Laws for the Simulation of Incremental Sheet Forming (ISF). (2005)

6. A. Hadoush, A.H. Van Den Boogaard, Substructuring in the implicit simulation of single point incremental sheet forming. International Journal of Material Forming. 2(3), 181-189 (2009)

7. M. Bambach, M. Cannamela, M. Azaouzi, G. Hirt, J.L. Batoz, Computer-aided tool path optimization for single point incremental sheet forming. Advanced Methods in Material Forming, Springer. 233-250 (2007)

8. M. Tisza, I. Panity, P. Z. Kovács, Experimental and numerical study of a milling machine-based dieless incremental sheet forming. International Journal of Material Forming. 3, 971-974 (2011)

9. J. Duflou, B. Lauwers, J. Verbert, Study on the achievable accuracy in single point incremental forming. Advanced Methods in Material Forming. 251 (2007)

10. T. Welo, Sheet metal forming in a prototyping method of ISF. Journal of Advances in Material Forming. 175-191 (2008)

11. C. Robert, On some computational aspects for incremental sheet metal forming simulations. International Journal of Material Forming. 1, 1195-1198 (2008)

12. Y. Luo, K. He, R. Du, A new sheet metal forming system based on incremental punching, part 2: machine building and experiment results. The International Journal of Advanced Manufacturing Technology. 51(5), 493-506 (2010) 